\title{
Seroepidemiological Study of Herpes Simplex Virus Type 1 in the Black Sea Region of Turkey
}

\author{
Füsun Artıran İğde', Zafer Yazıcı², Mahir Ĭğde ${ }^{3}$ \\ ${ }^{1}$ Department of Family Medicine, Faculty of Medicine, Ondokuz Mayıs University, Samsun, Turkey \\ ${ }^{2}$ Department of Virology, Faculty of Veterinary, Ondokuz Mayıs University, Samsun, Turkey \\ ${ }^{3}$ Division of Pediatric Allergy, Samsun Gynecology/Obstetric and Children Hospital, Samsun, Turkey
}

\begin{abstract}
Objective: In spite of the wide prevalence and growing incidence of herpes simplex virus type 1 infection (HSV-1), relatively few data have been published regarding the seroepidemiology of the infection in the Turkish population. The study was designed to determine the age and sex-specific seroepidemiology of HSV-1 infection in the Black Sea region of Turkey.
\end{abstract}

Material and Methods: Between March 1 and April 30, 2007, 1072 blood samples were randomly collected and examined by virus neutralization test (VNT) from patients aged 5-84 years who were referred to the University hospital outpatient clinics for various reasons in Black Sea Region of Turkey.

Results: Overall HSV-1 seroprevalence was 59.7\% (640/1072), and 58\% of males (283/490) and 62\% of females (357/582) were HSV-1 positive (p>0.05). In the group aged 15-19, seropositivity was significantly higher than in the group aged 19-24 ( $p=0.0333)$.

Conclusion: Subgroup analysis indicates a higher HSV-1 infection seropositivity than had been estimated in children and adolescents in the Black Sea region of Turkey. The high prevalence of HSV-1 infection in children underlines the need for education among potential risk groups.

Key Words: Herpes simplex virus, epidemiology, Turkey

\section{Introduction}

Herpes simplex virus infections are among the most common infectious diseases in humans (1). Infections with HSV types 1 and 2 are widespread in all human populations and result in persistent and latent infections. While HSV-1 is commonly responsible for orofacial infections and is usually transmitted during childhood and adolescence, HSV-2 is more likely to cause genital lesions $(2,3)$.

It is interesting that strong associations were recently observed between herpes infection and human immunodeficiency virus (HIV) seropositivity (4-7), and data on herpes infection antibody status may be useful in predicting those at greater risk of acquiring and transmitting HIV infection and may thus be valuable in guiding future efforts aimed at HIV (7).

The prevalence of HSV-1 infections overall and by age varies markedly by country, regions within a country, and population subgroups (8). Reliable data on the prevalence of HSV-1 serum antibodies provide an epidemiological measure of the population burden of these infections. Information on ageand sex-specific prevalence of herpes virus type 1 infections are essential in order to optimize herpes control strategies, which are growing in importance since accumulating data in- dicate that morbidity resulted from herpes infection shows increase.

The prevalence of HSV-1 varies widely across the world, although there have been no studies representing the seroprevalence of HSV type 1 generally in Turkish society (8).

The aim of this study was to determine the age and sexspecific seroprevalence of HSV-1 infection in the general population of the Black Sea region of Turkey using the Virus Neutralization Test (VNT), the effectiveness of which was confirmed in our previous study (9).

\section{Materials and Methods}

Between March 1 and April 30, 2007, 1072 blood samples taken for routine examinations in pediatric and adult outpatient clinics were randomly collected and examined by the virus neutralization test (VNT) from male and female subjects aged 5-84 years who applied to university hospital outpatient clinics for various reasons in the Black Sea Region of Turkey. The study was designed in accordance with the Helsinki Declaration and Good Clinical Practice guidelines and approved by the Institutional Ethical Committee.

The sera were divided into 12 different age groups;

Group 1, age 5-9; Group 2, age 10-14; Group 3, age 15- 
19; Group 4, age 20-24, Group 5, age 25- 29; Group 6, age 30-34, Group 7, age 35-39; Group 8, age 40-44; Group 9, age 45-49; Group 10, age 50-59; Group 11, age 60-69; and Group 12 , age 70 and above.

The samples were also assigned to one of three groups according to sexual activity.

According to recent data, the average age for the first experience of sexual intercourse in Turkey is 17.59 years for men and 19.05 for women (10). We regarded the group consisting of children and adolescents aged between 5 and 19 as sexually inactive, and individuals aged 20 and above as sexually active. Overall, these latter were referred to as the adult group, and were then further subdivided by gender into an adult male and an adult female group.

Blood samples were taken from children and then centrifuged at $3000 \mathrm{rpm}$ for 20 minutes at $4^{\circ} \mathrm{C}$, and serum was duly obtained. After centrifugation, each serum specimen was poured into another tube (Eppendorf, Germany), heat inactivated at $56^{\circ} \mathrm{C}$ for 30 minutes and stored at $-20^{\circ} \mathrm{C}$ until testing.

Human laryngeal epithelial carcinoma cell line (HEp-2) was grown in a $75-\mathrm{cm}^{2}$ cell culture flask (Orange Scientific, Belgium) in Eagle's minimum essential medium (EMEM, Sigma $\mathrm{GmbH}$, Germany) with $5 \%$ fetal calf serum (FCS, Sigma GmbH, Germany) and $1 \%$ penicillin/ streptomycin (Biochrome, KG) used for cell culture.

The KOS strain of HSV-1 was used in this study. Virus stock was prepared by infection of HEp-2 cells and incubation in EMEM containing $2 \%$ fetal calf serum at $37^{\circ} \mathrm{C}$ in $5 \% \mathrm{CO}_{2}$.

The infectivity value $\left(\mathrm{TCID}_{50}\right)$ of the virus was calculated using the microtiter technique on $\mathrm{HEp}-2$ cells according to the Karber formula (11), and to determine the prevalence of IgG antibodies against HSV-1, we used the Virus Neutralization Test (VNT) protocol described by Frey and Liess (12).

\section{Statistical Analysis}

All statistic analysis evaluations were performed by SPSS/ Windows Version 17.0, SPSS Inc., Chicago, IL, USA. Seropositivity proportion and linear trend of groups was compared using chi-square test and $p<0.05$ values were considered statistically significant.

\section{Results}

The overall HSV-1 seroprevalence was 59.7\% (640/1072). Tested samples were separated by age and sex into adult females, adult males, and children and adolescents. Of the 1072 participants, 377 (35.2\%) were male and 509 (47.4\%) were female, with 186 (17.4\%) children.

HSV-1 seroprevalence of the 12 age groups (Comparison of Linear Trend) is presented in Table 1. In Group 3 (age 1519) seropositivity was significantly higher than that in Group 4 $(p=0.0333)$, and Group 10 (age 50-59) age group seropositivity was significantly lower than that in Group $11(p=0.0249)$. All other age group seropositivity levels were similar $(p>0.05)$.

Most of the positive samples for anti-HSV type I antibodies presented low titers (77.04 \% for titers of 1:32 and less), high titers (1:128 and above) being more rarely observed (in $7.19 \%$ of cases) (Table 2).
Table 1. Number and percentage of anti HSV IgG seropositive samples in twelve age groups in the Black Sea Region of Turkey

\begin{tabular}{|lccc|}
\hline \multicolumn{4}{|c|}{ number of samples } \\
age groups yr (range) & tested & positive seropositivity (\%) \\
\hline $5-9$ & 125 & 85 & 68.00 \\
$10-14$ & 32 & 20 & 62.50 \\
$15-19$ & 29 & 20 & 68.97 \\
$20-24$ & 34 & 17 & 50.00 \\
$25-29$ & 35 & 19 & 54.29 \\
$30-34$ & 38 & 23 & 60.53 \\
$35-39$ & 194 & 122 & 62.89 \\
$40-44$ & 77 & 44 & 57.14 \\
$45-49$ & 83 & 45 & 54.22 \\
$50-59$ & 246 & 132 & 53.66 \\
$60-69$ & 110 & 69 & 62.73 \\
over 70 & 69 & 44 & 63.77 \\
Total & 1072 & 640 & 59.70 \\
\hline
\end{tabular}

Table 2. Distribution of the titer of serum anti-HSV type I, IgG positive samples in overall population from 12 age groups in the Black Sea Region of Turkey

\begin{tabular}{|c|c|c|c|c|c|c|}
\hline \multicolumn{7}{|c|}{ Number of samples with positive results } \\
\hline $\begin{array}{l}\text { Age group } \\
\text { yr (range) }\end{array}$ & $1: 4-1: 8$ & 1:16 & 1:32 & 1:64 & $\begin{array}{l}1: 128 \\
1: 256\end{array}$ & Total \\
\hline $5-9$ & 7 & 24 & 40 & 11 & 2 & \\
\hline $10-14$ & 4 & 4 & 8 & 4 & 0 & \\
\hline $15-19$ & 5 & 3 & 6 & 4 & 0 & \\
\hline $20-24$ & 2 & 2 & 10 & 2 & 2 & \\
\hline $25-29$ & 2 & 3 & 11 & 1 & 2 & \\
\hline $30-34$ & 2 & 8 & 8 & 3 & 0 & \\
\hline $35-39$ & 19 & 37 & 36 & 22 & 9 & \\
\hline $40-44$ & 7 & 15 & 12 & 5 & 4 & \\
\hline $45-49$ & 2 & 12 & 18 & 7 & 7 & \\
\hline $50-59$ & 22 & 43 & 40 & 19 & 10 & \\
\hline $60-69$ & 3 & 18 & 29 & 14 & 5 & \\
\hline Over 70 & 9 & 7 & 15 & 9 & 5 & \\
\hline \multirow[t]{2}{*}{ Total } & 84 & 176 & 233 & 101 & 46 & 640 \\
\hline & $13.13 \%$ & $27.50 \%$ & $36.41 \%$ & $15.78 \%$ & $7.19 \%$ & \\
\hline
\end{tabular}

When the high titers of anti-HSV type I IgG seropositivity for all age groups were compared, no difference between age groups was determined ( $p>0.05$ ). In addition, the distribution of the other antibody titers was similar between age groups ( $p>0.05)$ for all titers (Figure 1).

Overall HSV-1 seroprevalence was 58\% in males (283/490) and $61 \%$ in females $(357 / 582)(p>0.05)$. Similar gender distributions were determined in all age groups (Table 3 ) and no significant difference was observed ( $p>0.05)$. 
Table 3. Gender distribution of hsv i seropositivity for all age groups and for different genders

\begin{tabular}{|c|c|c|c|c|c|c|c|c|c|}
\hline \multicolumn{10}{|c|}{ Anti HSV IgG seropositivty } \\
\hline & & \multicolumn{3}{|c|}{ Male } & \multicolumn{3}{|c|}{ Female } & \multirow[b]{2}{*}{$\begin{array}{l}\text { chi square } \\
\text { value }\end{array}$} & \multirow[b]{2}{*}{$\begin{array}{c}p \\
\text { value }\end{array}$} \\
\hline & & $(+)$ & $(-)$ & $\begin{array}{c}\text { Seropositivity } \\
\text { (\%) }\end{array}$ & $(+)$ & $(-)$ & $\begin{array}{c}\text { Seropositivity } \\
\text { (\%) }\end{array}$ & & \\
\hline & $5-9$ & 53 & 25 & 68 & 32 & 15 & 68 & 0 & $>0.5$ \\
\hline & $10-14$ & 15 & 10 & 60 & 5 & 2 & 71 & 0.305 & 0.683 \\
\hline & $15-19$ & 5 & 5 & 50 & 15 & 4 & 79 & 2.565 & 0.205 \\
\hline & $20-24$ & 4 & 5 & 44 & 13 & 12 & 52 & 0.151 & $>0.5$ \\
\hline Age & $25-29$ & 7 & 3 & 70 & 12 & 13 & 48 & 1.393 & 0.285 \\
\hline \multirow[t]{8}{*}{ groups } & $30-34$ & 6 & 6 & 50 & 17 & 6 & 74 & 0.813 & 0.481 \\
\hline & $35-39$ & 42 & 35 & 55 & 80 & 37 & 68 & 3.806 & 0.068 \\
\hline & $40-44$ & 14 & 10 & 58 & 30 & 23 & 57 & 0.020 & $>0.5$ \\
\hline & $45-49$ & 20 & 18 & 53 & 25 & 20 & 56 & 0.071 & 0.828 \\
\hline & $50-59$ & 66 & 54 & 55 & 66 & 60 & 52 & 0.170 & 0.703 \\
\hline & $60-69$ & 35 & 23 & 60 & 34 & 18 & 65 & 0.298 & 0.693 \\
\hline & 70 and over & 16 & 13 & 55 & 28 & 15 & 65 & 1.600 & 0.218 \\
\hline & Total & 283 & 207 & 58 & 357 & 225 & 61 & 1.421 & 0.236 \\
\hline Chi square value & & & 6.5332 & & & 17.076 & & & \\
\hline$p$ value & & & 0.8355 & & & 0.1056 & & & \\
\hline
\end{tabular}

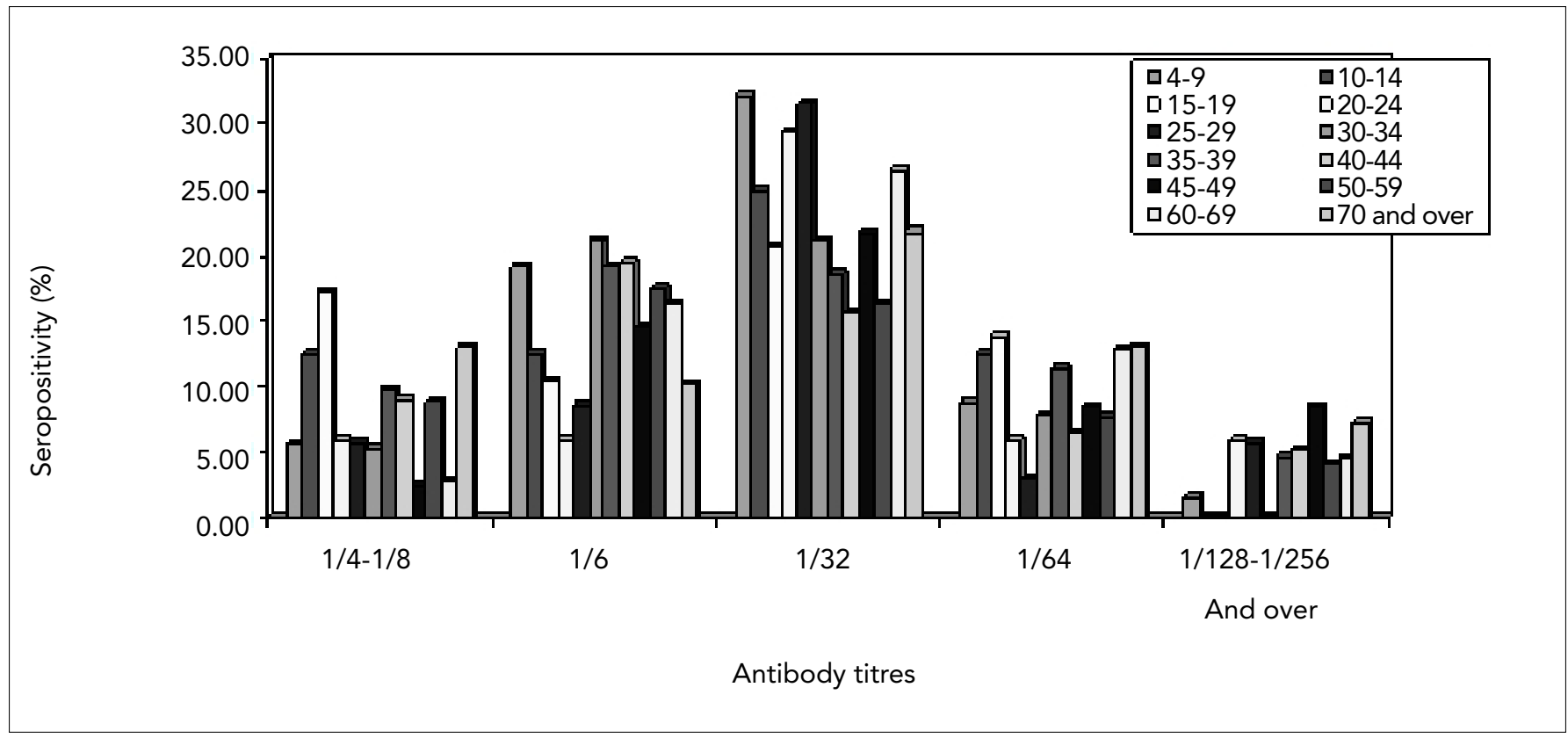

Figure 1. Comparative distribution of anti-HSV IgG antibody titers in the different age groups

When the data were re-evaluated in the light of the population's sexual activity, HSV-1 seroprevalence was $67.2 \%$ in the children and adolescent groups (125/186), and $58.1 \%$ in adults (515/886) (59.9\% in adult females (305/509) and $55.7 \%$ in adult males (210/377)). The only significant difference was that between the children-adolescent group and the adult male group $(p=0.011)$, all other levels being similar, and no differences were determined between groups (Figure 2).

\section{Discussion}

We studied the prevalence of antibodies against herpes simplex viruses type I by using the VNT method, in the general population of the Black Sea region of Turkey. Patients applying to the university outpatient clinics between March 1 and April 30,2007 , were included in the study. Since we did not access the patients' medical records we cannot be sure whether any 


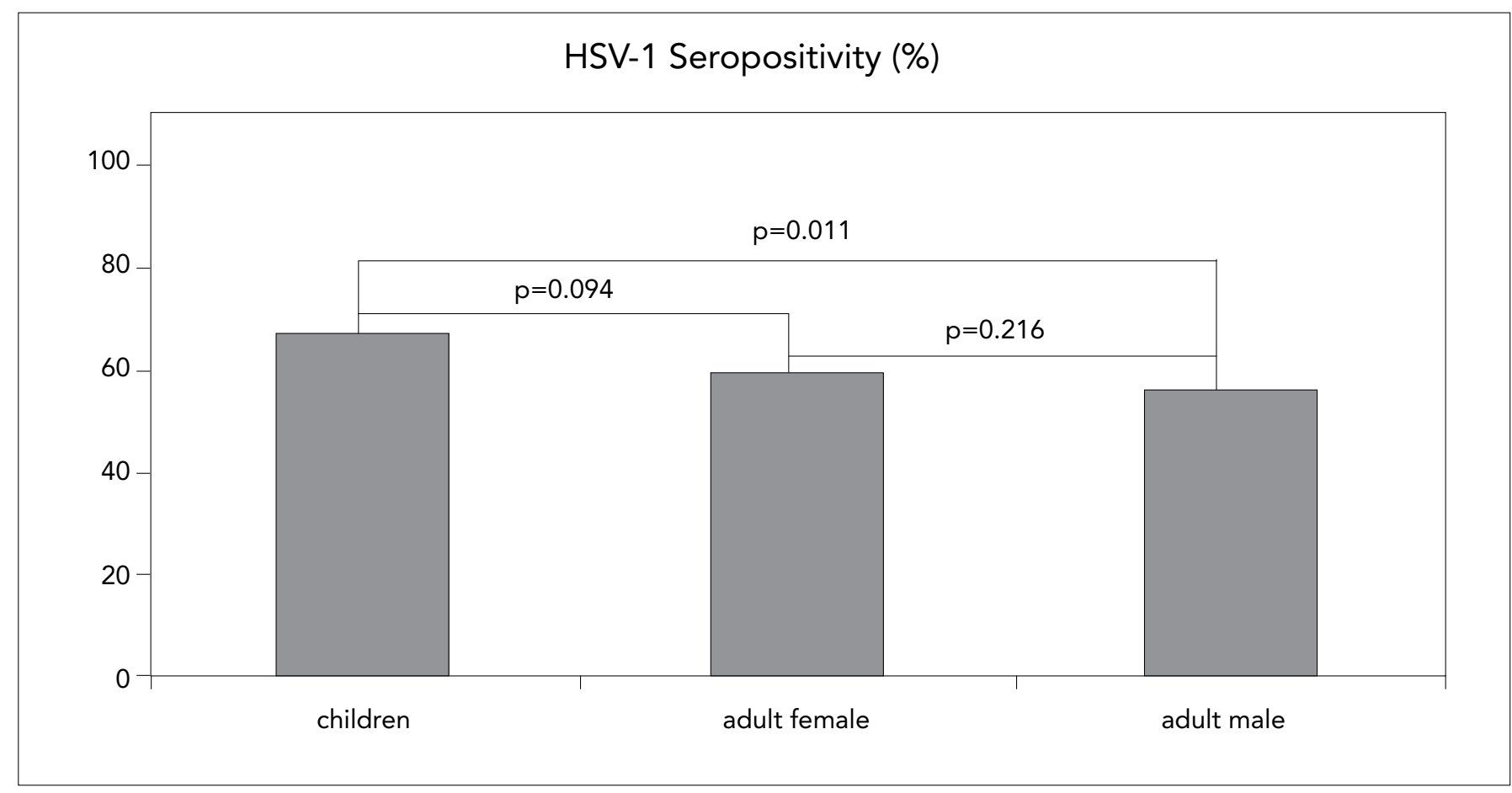

Figure 2. Comparative HSV-1 seropositivity of children, and adult male and female groups

particular diseases may have increased the frequency of HSV infections in the study. Our study could not be fully representative of the population in general. However, the conclusions we drew concerning age distribution and serotype specificity are not affected by this limitation.

Overall HSV-1 seropositivity was $59.7 \%$. Relatively few data have been published regarding the seroprevalence of herpes simplex infection in the Turkish population. Dolar et al. (13) reported that the prevalence of HSV-2 and HSV-1 antibodies was $4.8 \%$ and $85.3 \%$, respectively, in sexually active adults; $5.5 \%$ and $96 \%$ in blood donors; $5 \%$ and $98 \%$ in pregnant women, $17.3 \%$ and $93.6 \%$ in patients with genital warts; $8.3 \%$ and $97.3 \%$ in hotel staff; and $60 \%$ and $99 \%$ in sex workers. Their results are higher than ours. However, they investigated the prevalence of HSV-1 and HSV-2 in selected populations in Turkey, especially in high-risk groups. We consider that our results are a more accurate reflection of the general population status of Turkey.

Turkey straddles two continents, Asia and Europe. Different levels of HSV-1 seroprevalence have been observed in the general populations of Turkey's neighbors. The highest age-standardized HSV-1 seroprevalence was observed in Bulgaria (83.9\%) (14). In Greece the level was 72\% (15). Among healthy individuals in Syria, the highest prevalence of HSV-1 antibody was observed in the $>30$ year subgroup (94\% in males and $95 \%$ in females) (16). No data regarding HSV-1 seroprevalence were found from Turkey's other neighbors (Iraq, Iran, Armenia and Georgia). When those known HSV-1 seroprevalences in neighboring countries were compared with our results, the lowest overall HSV-1 infection seropositivity was determined in Turkey (59.7\%).

Secondly, considering the sexually inactive population in Turkey (10), our results show that HSV-1 infections occur in early in life in Turkey, as $67.2 \%$ of subjects aged 5 to 19 had specific antibodies. HSV-1 prevalence was reported as particularly high in children from Eriyeria in one study; $97 \%$ of those $>5$ years old were HSV-1 positive (17). Among New Mexico Navajo children, HSV-1 prevalence was $79 \%$ in those aged 1-5 (18). Similar results were found in Syria (55\% among children aged 1-5) (19). In Germany, HSV-1 prevalence was lower in children aged $1-5$ (31\%), rising to $46 \%-49 \%$ among those aged 6-16 (20). Among hospital patients in Israel, HSV-1 prevalence in children aged $2-4$ was $38 \%$, and $54 \%$ among those aged 15-17 (21). In England and Wales, HSV-1 prevalence was 46\%$49 \%$ among newborns, probably reflecting, at least in part, maternal antibody status, and $17 \%-27 \%$ among children aged 1-14 (22). In a cross-sectional study of 0-19 year old Swedish children in 2003, HSV-1 seroprevalence was $31 \%$ (23). In a European study using samples collected in 1989-2000, the seroprevalence for HSV-1 for the 5-9 age group in Belgium, England and the Netherlands was 25\%-35\%; seroprevalence for the $0-19$ age group in Bulgaria was $14 \%-15 \%$, compared to 23\%-27\% in the Czech Republic, 23\%-27\% in Finland and 12\% in Slovenia (14). Another recent study from Israel reported that the seroprevalence of HSV-1 increased with age in both sexes, reaching $57 \%$ by the age of 18 (24). There is a wide global variation in HSV-1 seropositivity in children and adolescents. This may be due to different socioeconomic status, life styles or association with different infections, such as HIV. Having evaluated these data, a modest seropositivity was determined among children and adolescents in Turkey. In most studies, however, HSV-1 seroprevalence either increases consistently with age across the age spectrum or else reaches a plateau after 30 . No such trend emerged from our results, and a more homogeneous distribution of seropositivity levels in 
different age groups was observed, with two exceptions. In the $15-19$ age group seropositivity $(68.97 \%)$ was significantly higher than that in the $20-24$ age group $(50 \%)(p=0.0333)$, and seropositivity in the $50-59$ age group (53.66\%) was significantly lower than that in the 60-69 age group (62.73) $(p=0.0249)$. All other age group seropositivity levels were similar $(p>0.05)$. In addition, when we compared HSV-1 seropositivity levels according to age at first sexual activity and to gender, the levels among the sexually inactive age group (67.2\%) and among sexually active adults (58.1\%) were high, but not significantly different. When we compared the sexually inactive age group seropositivity with adult groups; sexually inactive age group seropositivity was higher, but not significantly different from adult females $(59.9 \%)$, although significantly different from adult males (55.7\%). The earlier increase in HSV-1 seroprevalence in women observed in this study reflects the higher risk of genitally acquired HSV-1 in young women (25-30), which may reflect age-specific mixing patterns, with women having male partners on average older than themselves. The highest level, however, was determined in the sexually inactive age group. This is not in agreement with results obtained from other countries. This may again be due to changing life styles and environmental conditions, but maybe also to an increasing trend in HSV-1 infection or recent burden of infection.

When we analyzed different seropositivity titers for different age groups, we determined that high, intermediate and low titers were similarly distributed between the different age groups. In addition, overall high titers of seropositivity that may be regarded as recent or active infection status were observed at much lower levels $(7.19 \%$ for $1: 128$ and higher antibody titers) than the overall low titers of seropositivity that may be regarded as longstanding infection $(77.04 \%$ for $1: 4-$ 1:32). However, given the possible infection burden among the children and adolescent age group, high titer seropositivity among the children and adolescent age group might be expected at much higher levels than in other age groups, but our results suggest steadily progressing infection over a long time rather than such a potential infection burden.

Determining the etiology of high HSV-1seropositivity among children and adolescents will be of great importance in the future. There is no doubt that, whatever its causes, HSV1 is a very dangerous infection and effective measures should be taken, such as first determining the underlying etiological causes of high HSV-1 seropositivity.

When we compared overall HSV-1 infection according to gender, 58\% in males (283/490) and 61\% females (357/582), no significant difference was determined $(p>0.05)$. Gender distribution of seropositivity of HSV-1 antibodies was also similar for all age groups ( $p>0.05)$.

\section{Conclusion}

This study is the first cross-sectional and community-based investigation of the seroprevalence of HSV-1 lgG antibodies in the general Turkish population as opposed to studies of specific groups.

Overall HSV-1 seropositivity was lower compared to other countries in Europe, Asia and Africa. In the child age subgroup, HSV-1 infection seropositivity may be regarded as normal to high compared to neighboring countries. This difference may be significant, because childhood is followed by adolescence, and sexual activity begins during that period. Adolescent pregnancies that may occur during active HSV-1 infection may be complicated by serious problems. This may also be a sign of an increasing trend of HSV type 1 infection in this age group and may be the first step in a burden of infection. This potential risk should be monitored by periodic checks and some control measures should be taken, such as education of this age subgroup, and also HSV vaccination of adolescent girls in order to reduce the mortality and morbidity of HSV infection.

\section{Conflict of Interest}

No conflict of interest was declared by the authors.

\section{References}

1. Brugha R, Keersmaekers K, Renton A, Meheus A. Genital herpes infection: a review. Int J Epidemiol. 1997;26:698-709.

2. Nahmias AJ, Lee FK, Beckman-Nahmias S. Sero-epidemiological and sociological patterns of herpes simplex virus infection in the world. Scand J Infect Dis 1990;69:19-36.

3. Corey L, Spear PG. Infections with herpes simplex viruses. N Engl J Med. 1986;314:749-57.

4. Mbopi-Kéou FX, Grésenguet G, Mayaud P, Weiss HA, Gopal $\mathrm{R}$, Matta $\mathrm{M}$ et al. Interactions between herpes simplex virus type 2 and human immunodeficiency virus type 1 infection in African women: opportunities for intervention. J Infect Dis. 2000;182:1090-6.

5. Auvert B, Ballard R, Campbell C, Caraël M, Carton M, Fehler G et al. HIV infection among youth in a South African mining town is associated with herpes simplex virus-2 seropositivity and sexual behaviour. AIDS 2001;15:885-98.

6. Gwanzura L, McFarland W, Alexander D, Burke RL, Katzenstein D. Association between human immunodeficiency virus and herpes simplex virus type 2 seropositivity among male factory workers in Zimbabwe. J Infect Dis 1998;177:481-4.

7. Wald A, Link K. Risk of human immunodeficiency virus infection in herpes simplex virus type 2-seropositive persons: a meta-analysis. J Infect Dis 2002;185:45-52.

8. Smith JS, Robinson NJ. Age-specific prevalence of infection with herpes simplex virus types 2 and 1: a global review. J Infect Dis 2002;186:3-28.

9. Artiran Igde F, Igde M, Yazici Z, Okur Gumusova S, Birinci A, Sancak $R$ et al. Distribution of HSV-1 IgG antibodies by two methods comparing in Turkish atopic children. New Microbiol 2007;30:109-12.

10. Askun D, Ataca B. Sexuality related attitudes and behaviors of Turkish university students. Arch Sex Behav 2007;36:741-52.

11. Lennette, EH. General principles underlying laboratory diagnosis of viral and rickettsial infections. In.E.H.Lennette and J.N.Schmidtt (eds). Diagnostic procedures for virus and ricketsial disease. New York, Am.Public Health Association, 3rd edition, 1964;3:48-50.

12. Frey HR, Liess B. Vermehrungskinetik und verwendbarkeit einer stark cythopathogen VD-MD virusstammes für diagnostische untersuchugen mit der Mikrotiter Method. Zentralbl Veterinarmed B 1971;18:61-71.

13. Dolar N, Serdaroglu S, Yilmaz G, Ergin S. Seroprevalence of herpes simplex virus type 1 and type 2 in Turkey. J Eur Acad Dermatol Venereol 2006;20:1232-6. 
14. Pebody RG, Andrews N, Brown D, Gopal R, De Melker H, François $G$ et al. The seroepidemiology of herpes simplex virus type 1 and 2 in Europe. Sex Transm Infect 2004;80:185-91.

15. Papadogeorgakis H, Caroni C, Katsambas A, Pimenta JM, Avdeliodi $C$, Kotrotsou $T$ et al. Herpes simplex virus seroprevalence among children, adolescents and adults in Greece. Int J STD AIDS 2008;19:272-8.

16. Ibrahim Al, Kouwatli KM, Obeid MT. Frequency of herpes simplex virus in Syria based on type-specific serological assay. Saudi Med J 2000;21:355-60.

17. Ghebreidan H, Ruden U, Cox S, Wahren B, Grandien M. Prevelance of herpes simplex virus types 1 and 2, cytomegalovirus and varicella-zoster virus infection in Eriteria. J. Clin. Virol 1999:12;53-64.

18. Becker TM, Magder L, Harrison HR. The epidemiology of infection with the human herpesviruses in Navajo children. Am. J. Epidemiol 1988;127:1071-8.

19. Ibrahim Al, Kouwatli KM, Obeid MT. Frequency of herpes simplex virus in Syria based on type-specific serological assay. Saudi Med J 2000;21:355-60.

20. Wutzler P, Doerr HW, Färber I, Eichhorn U, Helbig B, Sauerbrei A et al. Seroprevalence of herpes simplex virus type 1 and 2 in selected German populations-relevance for the incidence of genital herpes. J. Med. Virol 2000;61:201-7.

21. Isacsohn $M$, Smetana $Z$, Rones $Z Z$, Raveh D, Diamant $Y$, Samueloff $A$ et al. A sero-epidemiological study of herpes virus type 1 and 2 infection in Israel. J Clin Virol 2002;24:85-92.

22. Vyse AJ, Gay NJ, Slomka MJ, Gopal R, Gibbs T, Morgan-Capner $P$ et al. The burden of infection with HSV-1 and HSV-2 in England and Wales: implications for the changing epidemiology of genital herpes. Sex Transm Infect 2000;76:183-7.

23. Tunback P, Bergstrom T, Andersson AS., Nordin P, Krantz I, Lowhagen GB. Prevalence of herpes simplex virus antibodies in childhood and adolescence: a cross sectional study. Scand. J. Infect. Dis 2003;35:498-502.

24. Davidovici BB, Gren M, Marouni MJ, Bassal R, Pimenta JM, Cohen $D$. Seroprevalence of herpes simplex virus type 1 and 2 and correlates of infection in Israel. J. Infect 2006;52:367-73.

25. Langenberg AG, Corey L, Ashley RL, Leong WP, Straus SE. A prospective study of new infections with herpes simplex virus type 1 and type 2: Chiron HSV Vaccine Study Group. N Engl J Med 1999;341:1432-8.

26. Ross J, Smith I, Elton R. The epidemiology of herpes simplex types 1 and 2 infection of the genital tract in Edinburgh 1978-91. Genitourin Med 1993;69:381-3.

27. Gibson JJ, Hornung CA, Alexander GR, Lee FK, Potts WA, Nahmias AJ. A cross-sectional study of herpes simplex virus type 1 and 2 in college students: occurrence and determinants of infection. J Infect Dis 1990;162:306-12.

28. Peutherer JF, Smith IW, Robertson DH. Genital infection with herpes simplex virus type 1. J Infect 1982;2:33-5.

29. Lavery HA, Connolly JH, Russell JD. Incidence of genital herpes in Northern Ireland in 1973-83 and herpes simplex types 1 and 2 isolated in 1982-84. Genitourin Med 1986;62:24-7.

30. Barton IG, Kinghorn GR, Najem S, Al-Omar LS, Potter CW. Incidence of herpes simplex virus types 1 and 2 isolated in patients with herpes genitalis in Sheffield. Br J Vener Dis 1982;58:44-7. 